\title{
Collaborative Implementation of Stereotactic Ablative Body Radiotherapy - A model for the safe implementation of complex radiotherapy techniques in Australia
}

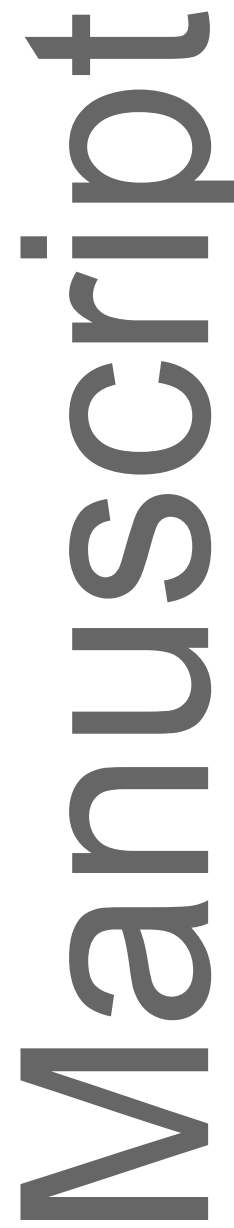

E.Hau ,F. Hegi-Johnson, C Atkinson, J. Barber, L.H. Browne, Y. Chin , P. Dwyer , P. H.Graham, J O'Hare, D. Lu, M.Rains, C. Ragusa, L. Foessel, K. Small, K. Unicomb, K. West, S. White, A.Last, J.Ludbrook, M Azzi, N Ahern N, K. Van Tilburg, S.K. Vinod, X.Ma, R. Yeghiaian-Alvandi

\section{ABSTRACT}

Introduction

Stereotactic ablative radiotherapy (SABR) for lung cancer is a modality of treatment which has improved outcomes for lung cancer patients. However, radiotherapy for lung cancer is under-utilised and fewer than half of elderly patients with non-small cell lung cancer (NSCLC receive active treatment. The purpose of this study is to report on a collaboration in implementing a NSCLC SABR (stereotactic ablative body radiation) program safely, efficiently and uniformly across several centres including regional sites. The first aim of this paper is to detail the collaboration and implementation which started in 2013 and is ongoing. The second aim of this paper is to document early toxicities and quality of life outcomes.

\section{Method}

A tripartite approach was used to develop the protocol and networks required for the implementation of SABR across multiple sites in NSW. Departments starting the programmes were supported and physics credentialing with central site submission required before commencing treatment. Additional ongoing support was available via an email discussion group involving all members of the collaboration.

Results

Between 22/7/2013 and 22/2/2016, 41 patients were enrolled with 34 patients in active follow up. The toxicity profile so far is similar to those of published studies with no appreciable effect on quality of life outcomes.

Conclusion

This is the author manuscript accepted for publication and has undergone full peer review but has not been through the copyediting, typesetting, pagination and proofreading process, which may lead to differences between this version and the Version of Record. Please cite this article as doi: 10.1111/ajco.13277.

This article is protected by copyright. All rights reserved. 
The collaboration formed an effective framework in facilitating the implementation of SABR across several sites in NSW and could be used as a model for the safe and uniform implementation of new technologies in Australia.

Keywords: Stereotactic, stereotactic body, radiation, radiotherapy, lung cancer

Introduction

Australia is one of the most urbanised countries in the world with major population centres concentrated particularly along the southern and eastern coastline. Until recently, radiotherapy centres were concentrated in large cities but the development of new regional centres has facilitated improved access to radiotherapy. As the majority of centres in Australia function independently, there are significant challenges in implementing new treatment technologies safely and uniformly across a number of sites.

Stereotactic ablative radiotherapy (SABR) for lung cancer is one such new modality of treatment which has improved outcomes for lung cancer patients. A population based study in the Netherlands demonstrated that the introduction of SABR was associated with a $16 \%$ increase in radiotherapy use and a decline in the proportion of untreated elderly patients. This increase in radiotherapy utilisation was associated with improvement in overall survival ${ }^{1}$. However, radiotherapy for lung cancer in general is under-utilised both in Australia ${ }^{2,3}$ and worldwide ${ }^{4}$ and fewer than half of elderly patients with non-small cell lung cancer (NSCLC) receive active treatment ${ }^{5,6}$.

SABR is now the standard of care over conventional radiotherapy for peripherally located NSCLC in patients who are medically inoperable or refuse surgery ${ }^{7}$.Moreover, in patients with operable disease, a pooled analysis from two randomised controlled trials, STARS(NCT00840749) and ROSEL (NCT00687986) has suggested that SABR could also be an option given the surgical mortality rate of $4 \%$ and grade $3-4$ post-operative complication rate of $44 \%{ }^{8}$.

Lung SABR is technically complex, requiring multidisciplinary expertise and significant quality assurance for safe and effective treatment. The potential for harm is higher than for conventional treatment given the large doses per fraction delivered to small mobile volumes. Toxicity is increased for centrally located tumours ${ }^{9,10}$ though a systematic review of 563 tumours in 315 patients reported a treatment related mortality of $2.7 \%$ overall and $1.0 \%$ when the biologically equivalent normal tissue dose was $\leq 210 \mathrm{~Gy}^{11}$ which is significantly lower than that reported in the surgical literature ${ }^{12}$. 
The purpose of this study is to report on a collaboration in implementing a lung cancer SABR program safely, efficiently and uniformly across several centres including regional sites. The study is a prospective phase II trial aiming to enrol 100 patients treated with SABR. The first aim of this paper is to detail the collaboration and implementation which started in 2013 and is ongoing. The second aim of this paper is to document early toxicities and quality of life outcomes.

\section{Methods:}

Figure 1 illustrates the implementation process of this collaboration. Initially a tripartite committee was formed consisting of radiation oncologist, radiation therapist and physicists with a special interest and expertise in treating lung SABR. Building on an initial broad inclusive and consultative effort, the second phase was largely driven by a relatively small team with representation from each of the tripartite groups. A series of teleconferences and email groups were set up to allow the exchange of ideas into the development of the structure of the collaboration and an evidence based treatment protocol. The recommendations were based on published literature, existing ongoing clinical trial protocols and expert opinion. Consensus was achieved in the majority of issues.

The ethics approved protocol encompasses all stages of the planning and treatment process including patient selection, equipment specifications, immobilisation, motion management, contouring of tumour and normal structures, dose prescription, dose constraints, planning objectives, physics quality assurances and credentialing.

Departments starting the programmes have been supported by site initiation teleconferences with established SABR departments and knowledge sharing. Physics credentialing with central site submission is required before centres can start treatment. Additional ongoing support was available via an email discussion group involving all members of the collaboration although as experience developed the need for this reduced throughout the running of the study.

The protocol also covers treatment of centrally placed tumours. For these cases, an option is available for dose reduction if the normal tissue constraints are not met. However, since a reduction in prescribed dose is associated with lower local control, the plans may be reviewed by an independent site to see if they may be improved before dose reduction occurs. All clinical information, complete plans in DICOM (Digital Imaging and Communications in Medicine) format and all diagnostic and follow up imaging are stored centrally in a secured server at St George Hospital and managed by a dedicated trial data manager. All procedures follow the requirements of Good Clinical Practice (CPMP/ICH/135/95) to maintain the accuracy, integrity and security of data, and to protect the confidentiality of trial participants. The trial is approved by the South Eastern Sydney Local Health District Human Research Ethics Committee. All participating sites obtained authorisation from local research governance before the study is commenced. The trial is registered to the Australian New Zealand Clinical Trials Registry (ANZCTR.org.au Identifier: ACTRN12614000478617).

An independent data and safety committee has also been formed and will be tasked with providing review of the trial progress and safety.

\section{Eligibility Criteria}

Patients with pathological and/or imaging diagnosis of NSCLC are eligible for inclusion in the study. Tumours stage T1-T2, N0M0 in accordance with AJCC Staging Manual $6^{\text {th }}$ edition 
and size not exceeding $5 \mathrm{~cm}$. Patients must be older than 18 years of age, have a ECOG performance status score of 2 or lower, and must be able to lie flat and comply with the requirements of simulation and treatment. Patients with previous thoracic radiotherapy are permitted provided lung V20 $<15 \%$ on previous treatment and no overlap with intended current radiotherapy field. Previous history of malignancy is accepted provided the previous malignancy is in remission. The consensus of multi-disciplinary team discussion may be used to determine whether the current lung lesion is lung primary as opposed to metastatic disease. All patients provided written informed consent.

\section{Treatment}

Respiratory motion must be considered to account for the effect on target positioning and reproducibility. Patients may be treated in free breathing, or with manoeuvres to reduce respiratory motion, as per departmental protocol. Acceptable manoeuvres include: abdominal compression, linear accelerator beam gating with the respiratory cycle, tumour tracking, and active breath-holding.

3D-conformal and Intensity Modulated Radiation Therapy (IMRT) are both acceptable.

Volumetric Modulated Arc Therapy (VMAT) is also acceptable.

The dose prescription is dependent on location and is detailed in Supplementary Figure 1.

Peripheral tumours with GTV $<1.5 \mathrm{~cm}$ from ribs are treated with 48Gy in 4 fractions whilst those $\geq 1.5 \mathrm{~cm}$ from ribs are treated with $54 \mathrm{~Gy}$ in 3 fractions with 2-3 treatments delivered per week. Central lesions are treated 50Gy in 5 fractions. Dose reduction to $47.5 \mathrm{~Gy}$ in 5 fractions or $45 \mathrm{~Gy}$ in 5 fractions is allowed after central review of the plan. Where SABR is not deemed to be suitable, the clinician may elect to treat the patient using other approaches such as hypofractionated or conventionally fractionated therapy.

\section{Credentialing}

Centres must demonstrate they meet the minimum equipment requirements, can achieve dosimetric accuracy to $4 \%$ and systematic accuracy of $<2 \mathrm{~mm}$. Centres are required to submit a dummy plan, and demonstrate safe delivery in a phantom prior to be permitted to join the study. Participating centres must be able to deliver treatment with precise agreement of target setup and radiation centre.

Centres are to submit documentation showing $\leq 1 \mathrm{~mm}$ average difference in setup and radiation centres (e.g. Winston-Lutz test results for gantry, collimator and couch angles to be used clinically).

\section{Image Verification}

Verification imaging capable of visualizing the target in 3D, such as Cone Beam CT (CBCT), is mandatory. Image registration and setup corrections are to be based on the soft tissue target. Verification is required prior to delivery and following delivery to identify any possible errors.

\section{Follow-up}

During the first two years following treatment completion, patients are seen every 3 months with chest CT scan and 6 monthly pulmonary function tests. In the third year, follow-up takes place every 6 months with chest CT scan and pulmonary function tests until 5 years after treatment. Toxicity, disease progression, metastasis and death are documented. Patient quality-of-life is measured at each follow-up time point using the European Organization for Research and Treatment of Cancer (EORTC) Quality of Life Core Questionnaire (QLQ-C30) and lung module (QLQ-LC13). Common toxicity criteria data is collected at 4 weeks post 
treatment and then at 3 monthly intervals for the first 2 years and then 6 monthly until 5 years. The maximum toxicity over the follow up to date is reported.

Results

Between 22/7/2013 and 22/2/2016, 41 patients were enrolled with 34 patients in active follow up.

Baseline data was available for 38 patients at the time of analysis.

Since 2013, the number of sites as part of this collaboration has increased and now includes St George, Nepean, Crown Princess Mary Westmead, Blacktown, Calvary Mater (Newcastle), Northern NSW Cancer Institute (Lismore), Mid North Cancer Institute (Port Macquarie, Coffs Harbour), Central Coast Cancer Centre (Gosford Hospital), Liverpool and Campbelltown Hospitals.

The collaboration has been successful in facilitating the implementation of SABR in a number of sites and has allowed peer review of challenging cases by means of a group email. Table 1 details the patient baseline characteristics. The median age is 75.5 and patients were evenly distributed in terms of sex. The most commonly used dose/fractionation regime was 48Gy in 4\# (Supplementary Table 1). Seven patients who were screened did not have SABR treatment and the reasons are listed in Supplementary Table 2. Patient 1 had a central tumour and the airway constraints were not met. After discussion between the collaboration members it was decided to treat the patient with a hypofractionated regime. Patient 4 was not treated with SABR due to several constraints not being met including lung, chest wall and conformity indexes. Patient 7 also did not receive SABR due to not meeting the lung constraints.

For the toxicity analysis, data was available for thirty-five patients of the total forty-one patients recruited. Data for six patients were not collected (two not collected due to new recruitment data not available at the time of analysis; 1 withdrawn; 1 not treated as cancer; 2 data not available due to late submission). Considering all enrolled patients, follow-up period varied from 4 weeks to 30 months with a median follow-up of 6 months. The highest toxicity scores over follow-up are presented in Table 2.

The rate of Grade $\geq 2$ toxicity is low except for dyspnoea. Grade 2 dyspnoea was recorded for 11 of 35 patients and 1 patient experienced grade 3 dyspnoea. There were only 2 other grade 3 events, one case of atelectasis and one of pneumonitis. The total rate of any grade 3 toxicity was $8.6 \%$. There were no grade 4 toxicities.

There has been 2 serious adverse events. One patient was admitted into hospital for dyspnoea (CTC V4.0, Grade 2) and cough (Grade 2) 36 days following treatment while another one was admitted 56 days following treatment for type 1 respiratory failure secondary to radiation pneumonitis on a background of COPD and subsequently discharged with home oxygen. No treatment related deaths have been recorded.

Table 3 details baseline and follow-up dyspnoea. Dyspnoea was present at baseline for 29 patients (76\%). When compared with baseline (before SABR) dyspnoea rates, 10 of $35(29 \%)$ patients experienced a one category increase in dyspnoea rate. No patient experienced a greater than 1 category increase in dyspnoea. Based on the limited number of patients and follow up, the overall quality of life remained relatively stable throughout follow-up to 18 months (Supplementary Table 3). 


\section{Discussion:}

Lung SABR is technically complex, requiring multidisciplinary expertise for safe and effective delivery. Although generally well tolerated, SBRT can result in serious complications including death ${ }^{13}$. Australian and New Zealand guidelines exist for the safe practice of SABR and recommend that it be carried out in an organised programme ${ }^{14}$. The National Health Service UK practice guidelines states that 'no department with SABR should treat less than 25 patients over a year with this technique, in order to maintain the professional competencies of all members of the treating team ${ }^{, 15}$. This may be possible in the UK with a more centralised service but is difficult to implement in Australia and New Zealand given the wide geographical distribution of services with the establishment of regional networks.

The benefit of this collaboration is that it promotes and facilitates the safe practice of SABR given the large distances and also large numbers of smaller centres. The development of a common protocol used amongst several sites which incorporate the principles in the Australian and New Zealand guidelines serve to reduce the variability of practice across sites. The collaboration also facilitates the recommendation in the guideline which specifically states that centres implementing SABR actively seek collaborations with more experienced centres and that standardisation of technical and clinical protocol at a state or national level should be pursued ${ }^{14}$.

This ongoing study involves the prospective collection of all clinical information, radiation plans, diagnostic and progress imaging which may allow future studies to be conducted including comparison of outcomes to international published studies and the investigation of predictors of toxicity and tumour control. The collaboration allows regular review of the protocol by members of the collaboration such that any new developments in the treatment may result in modifications of the current protocol. An independent data and safety monitoring committee also reviews the clinical data to ensure that that the treatment is safe and that unexpected toxicities will prompt a review of the practice and protocol.

Our preliminary analysis of the first 41 patients enrolled into the study suggests a low rate of toxicity consistent with that reported in the literature. Only three grade 3 events were recorded, resulting in an overall rate of $8.6 \%$, consistent with most reports of a rate of $<10 \%{ }^{16}$. The baseline dyspnoea rate is high at $76 \%$ but may be expected in a population not considered suitable for surgery and is consistent with published data. ${ }^{17}$ Around $29 \%$ of patients experienced aggravated dyspnoea defined as an increase in grade of dyspnoea of $\geq 1$ category above baseline. The data regarding this is more limited but a single report looking at 28 patients with medically inoperable Stage I tumours found the rate of aggravated dyspnoea at $40 \%{ }^{17}$

The minimum departmental caseload by international guidelines such as the UK which specifies a minimal caseload of 25 per annum is unlikely to be achievable by the majority of Australian sites. However, limiting the use of SABR to high volume centres would compromise access to this therapy. ${ }^{18}$ As such, this collaborative framework allows SABR to be safely and rapidly applied across several Australian centres including regional sites.

Conclusions: This collaborative approach has led to uniform adoption of clinical and technical protocols, and facilitated large-scale data pooling of SABR patient information across NSW. This model could be used as the basis for a national collaboration, and the development of accreditation and credentialing procedures for Australian departments. The initial short term follow-up toxicity outcomes are similar to those reported internationally.

Conflicts of Interest: 
Dr Fiona Hegi-Johnson

1. Astra Zeneca: honoraria, advisory board and clinical trial funding

2. Victorian Comprehensive Cancer Centre (VCCC): Clinical Trial Funding

3. Peter MacCallum Foundation: Fellowship funding

Dr Eric Hau

1.Astra Zeneca: honoraria, advisory board

1. Palma D, Visser O, Lagerwaard FJ, Belderbos J, Slotman BJ, Senan S. Impact of introducing stereotactic lung radiotherapy for elderly patients with stage I non-small-cell lung cancer: a population-based time-trend analysis. J Clin Oncol 2010;28:5153-9.

2. Mitchell PL, Thursfield VJ, Ball DL, et al. Lung cancer in Victoria: are we making progress? Med J Aust 2013;199:674-9.

3. Vinod SK, O'Connell DL, Simonella L, et al. Gaps in optimal care for lung cancer. J Thorac Oncol 2008;3:871-9.

4. Vinod SK. International patterns of radiotherapy practice for non-small cell lung cancer. Semin Radiat Oncol 2015;25:143-50.

5. Higton AM, Monach J, Congleton J. Investigation and management of lung cancer in older adults. Lung Cancer 2010;69:209-12.

6. Peake MD, Thompson S, Lowe D, Pearson MG, Participating C. Ageism in the management of lung cancer. Age Ageing 2003;32:171-7.

7. Nyman J, Hallqvist A, Lund JA, et al. SPACE - A randomized study of SBRT vs conventional fractionated radiotherapy in medically inoperable stage I NSCLC. Radiother Oncol 2016;121:1-8.

8. Chang JY, Senan S, Paul MA, et al. Stereotactic ablative radiotherapy versus lobectomy for operable stage I non-small-cell lung cancer: a pooled analysis of two randomised trials. Lancet Oncol 2015;16:630-7.

9. Timmerman R, McGarry R, Yiannoutsos C, et al. Excessive toxicity when treating central tumors in a phase II study of stereotactic body radiation therapy for medically inoperable early-stage lung cancer. J Clin Oncol 2006;24:4833-9.

10. Haseltine JM, Rimner A, Gelblum DY, et al. Fatal complications after stereotactic body radiation therapy for central lung tumors abutting the proximal bronchial tree. Pract Radiat Oncol 2016;6:e27-33.

11. Senthi S, Haasbeek CJ, Slotman BJ, Senan S. Outcomes of stereotactic ablative radiotherapy for central lung tumours: a systematic review. Radiother Oncol 2013;106:276-82. 
12. Ferguson MK, Lehman AG. Sleeve lobectomy or pneumonectomy: optimal management strategy using decision analysis techniques. Ann Thorac Surg 2003;76:1782-8.

13. Lo SS, Sahgal A, Chang EL, et al. Serious complications associated with stereotactic ablative radiotherapy and strategies to mitigate the risk. Clin Oncol (R Coll Radiol) 2013;25:378-87.

14. Foote M, Bailey M, Smith L, et al. Guidelines for safe practice of stereotactic body (ablative) radiation therapy. J Med Imaging Radiat Oncol 2015;59:646-53.

15. Kirkbride P BK, Cassoni A et al. on behalf of the National SBRT NRIG Subgroup. Stereotactic body radiotherapy, guidelines for commissioners, providers and clinicians in England 2011. National Cancer Action Team, NHS , 2010 2010; http://www.cancerresearchuk.org/cancer-

info/prod consump/groups/cr common/@nre/@new/@gen/documents/generalcontent/cr 07472 9.pdf.

16. Chi A, Liao Z, Nguyen NP, Xu J, Stea B, Komaki R. Systemic review of the patterns of failure following stereotactic body radiation therapy in early-stage non-small-cell lung cancer: clinical implications. Radiother Oncol 2010;94:1-11.

17. Paludan M, Traberg Hansen A, Petersen J, Grau C, Hoyer M. Aggravation of dyspnea in stage I non-small cell lung cancer patients following stereotactic body radiotherapy: Is there a dosevolume dependency? Acta Oncol 2006;45:818-22.

18. Vinod SK, Simonella L, Goldsbury D, Delaney GP, Armstrong B, O'Connell DL. Underutilization of radiotherapy for lung cancer in New South Wales, Australia. Cancer 2010;116:686-94. 
Forming tripartite committee

Radiation Oncologist, Radiation Physicist, Radiation Therapist
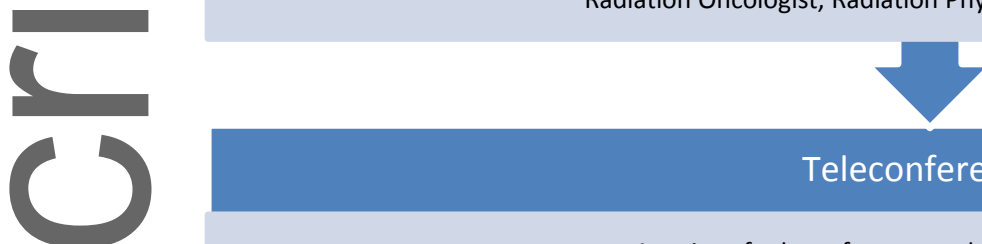

Teleconferences

A series of teleconfernces and setup of email groups

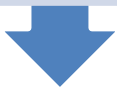

Developed Protocols

Ethics approved based on best available evidence, immobilisation, motion management, contouring, prescription pages, equipment specifications

\section{Implementation of SBRT across several sites}

Physics credentialling before enrolment, recruitment, supporting site intiation meeting, initial review of plans

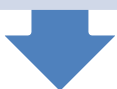

\section{Data collection, safety monitoring and ongoing support}

Central clinical and data storage, email and teleconference discussion of cases, plan review, independent data and saftey monitoring committee, protocol revision based on updated evidence or feedback from the collaborative

\section{Figure Legends}

Figure 1 Flowchart of the implementation process 


\section{Patient characteristics and demographics $(n=38)$}

Variable

$\mathrm{n}(\%)$

Gender

\begin{tabular}{|c|c|c|}
\hline & Male & $19(50)$ \\
\hline & Female & $19(50)$ \\
\hline \multicolumn{3}{|l|}{ ECOG status } \\
\hline & 0 & $18(47)$ \\
\hline & 1 & $14(37)$ \\
\hline & 2 & $6(16)$ \\
\hline
\end{tabular}

Smoking status

\begin{tabular}{|l|l|r|}
\hline & never smoked & $3(8)$ \\
\hline & ex-smoker & $27(71)$ \\
\hline & current smoker & $8(21)$ \\
\hline
\end{tabular}

Baseline Exercise tolerance

\begin{tabular}{|l|l|r|}
\hline & less than $100 \mathrm{~m}$ & $10(26)$ \\
\hline & between $101 \mathrm{~m}$ to $500 \mathrm{~m}$ & $15(40)$ \\
\hline & greater than $500 \mathrm{~m}$ & $13(34)$ \\
\hline
\end{tabular}

Baseline dyspnoea grading (including SABR and non-SABR treated patients)

\begin{tabular}{|c|c|c|}
\hline & $0=$ No dyspnoea & $9(23)$ \\
\hline & 1 = Shortness of breath with moderate exertion & $22(58)$ \\
\hline & $\begin{array}{l}2 \text { = Shortness of breath with minimal exertion; } \\
\text { limiting instrumental ADL }\end{array}$ & $6(16)$ \\
\hline & $\begin{array}{l}3 \text { = Shortness of breath at rest; limiting self care } \\
A D L\end{array}$ & $1(3)$ \\
\hline & $\begin{array}{l}4 \text { = Life threatening consequences; urgent } \\
\text { intervention indicated }\end{array}$ & $0(0)$ \\
\hline \multicolumn{3}{|c|}{ Baseline dyspnoea grading (SABR treated patients) $(n=32)$} \\
\hline & $0=$ No dyspnoea & $4(12)$ \\
\hline & $1=$ Shortness of breath with moderate exertion & $22(69)$ \\
\hline & $\begin{array}{l}2 \text { = Shortness of breath with minimal exertion; } \\
\text { limiting instrumental } A D L\end{array}$ & $5(16)$ \\
\hline & $\begin{array}{l}3 \text { = Shortness of breath at rest; limiting self care } \\
A D L\end{array}$ & $1(3)$ \\
\hline & $\begin{array}{l}4 \text { = Life threatening consequences; urgent } \\
\text { intervention indicated }\end{array}$ & 0 \\
\hline \multicolumn{2}{|c|}{ Previous history of malignancy $(n=30)$} & $10(33)$ \\
\hline \multicolumn{3}{|l|}{ Primary tumour site } \\
\hline & Central tumour & $6(16)$ \\
\hline & Peripheral tumour & $32(84)$ \\
\hline \multicolumn{3}{|c|}{ Histopathology Confirmation $(n=29)$} \\
\hline & Squamous cell carcinoma & $11(39)$ \\
\hline & Adenocarcinoma & $13(43)$ \\
\hline & Large cell undifferentiated & $1(4)$ \\
\hline
\end{tabular}

This article is protected by copyright. All rights reserved. 


\begin{tabular}{|c|c|}
\hline Bronchoalveolar carcinoma (BAC) & 0 \\
\hline $\begin{array}{l}\text { Others (poorly differentiated carcinoma, mix } \\
\text { non-small cell/large cell carcinoma) }\end{array}$ & $4(14)$ \\
\hline & Median (range) \\
\hline Age in years & $75.5(51-89)$ \\
\hline ECOG status & $1(0-2)$ \\
\hline Smoker pack/years $(n=35)$ & $40(10-125)$ \\
\hline Primary tumour size (mm) & $29(1.6-52)$ \\
\hline Charlson Comorbidity Index & $1(0-4)$ \\
\hline \multicolumn{2}{|c|}{ Baseline Spirometry ( $n=37)$} \\
\hline FEV1 actual (L) & $1.4(0.34-3.8)$ \\
\hline predicted $\%$ & $65.7(21-105.2)$ \\
\hline FVC actual (L) & $2.68(0.81-5.13)$ \\
\hline predicted \% & $90(36-119)$ \\
\hline DLCO predicted \% $(n=33)$ & $55.2(16.6-131)$ \\
\hline
\end{tabular}


Table 2 Maximum toxicity over available follow-up

\begin{tabular}{|c|c|c|c|c|c|}
\hline $\mathrm{n}=35$ & G0 & G1 & G2 & G3 & G4 \\
\hline Atelectasis & 25 & 9 & 0 & 1 & 0 \\
\hline Bronchopulmonary haemorrhage & 34 & 1 & 0 & 0 & 0 \\
\hline Cough & 14 & 18 & 3 & 0 & 0 \\
\hline Dyspnoea & 8 & 15 & 11 & 1 & 0 \\
\hline Hypoxia & 32 & 2 & 1 & 0 & 0 \\
\hline Pleural effusion & 33 & 2 & 0 & 0 & 0 \\
\hline Pneumonitis & 32 & 1 & 1 & 1 & 0 \\
\hline Pulmonary fibrosis & 25 & 9 & 1 & 0 & 0 \\
\hline Dysphagia & 32 & 1 & 2 & 0 & 0 \\
\hline Dermatitis radiation & 34 & 1 & 0 & 0 & 0 \\
\hline Chest wall pain & 24 & 10 & 1 & 0 & 0 \\
\hline Bronchial fistula & 35 & 0 & 0 & 0 & 0 \\
\hline Bronchopleural fistula & 35 & 0 & 0 & 0 & 0 \\
\hline Pleural haemorrhage & 35 & 0 & 0 & 0 & 0 \\
\hline Tracheal fistula & 35 & 0 & 0 & 0 & 0 \\
\hline Pericardial effusion & 35 & 0 & 0 & 0 & 0 \\
\hline Esophageal fistula & 35 & 0 & 0 & 0 & 0 \\
\hline Esophageal stenosis & 35 & 0 & 0 & 0 & 0 \\
\hline Esophageal ulcer & 35 & 0 & 0 & 0 & 0 \\
\hline Superficial soft tissue fibrosis & 35 & 0 & 0 & 0 & 0 \\
\hline Brachial plexopathy & 35 & 0 & 0 & 0 & 0 \\
\hline
\end{tabular}

Table 3 Baseline vs follow-up dyspnoea

All patients $n=38^{*}$

Follow up dyspnoea grading

This article is protected by copyright. All rights reserved. 


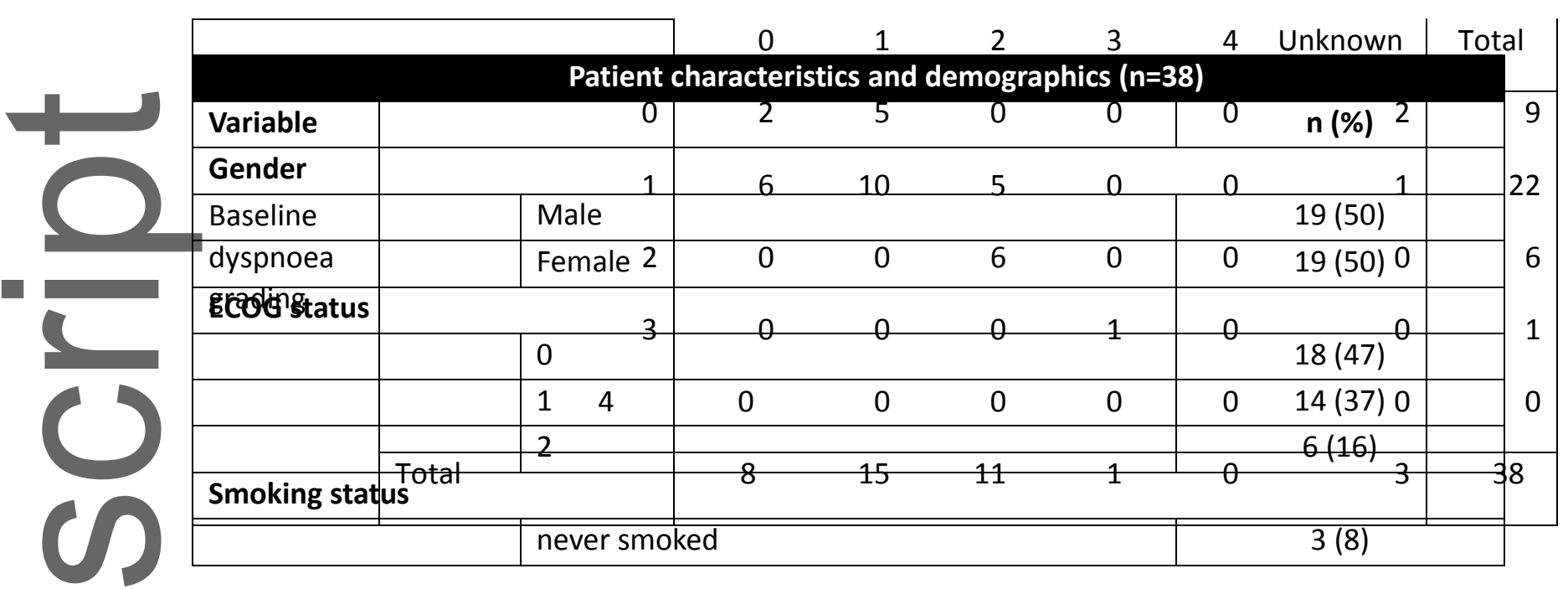




\begin{tabular}{|c|c|c|}
\hline & ex-smoker & $27(71)$ \\
\hline & current smoker & $8(21)$ \\
\hline \multicolumn{3}{|c|}{ Baseline Exercise tolerance } \\
\hline & less than $100 \mathrm{~m}$ & $10(26)$ \\
\hline & between $101 \mathrm{~m}$ to $500 \mathrm{~m}$ & $15(40)$ \\
\hline & greater than $500 \mathrm{~m}$ & $13(34)$ \\
\hline \multicolumn{3}{|c|}{ Baseline dyspnoea grading (including SABR and non-SABR treated patients) } \\
\hline & $0=$ No dyspnoea & $9(23)$ \\
\hline & $1=$ Shortness of breath with moderate exertion & $22(58)$ \\
\hline & $\begin{array}{l}2 \text { = Shortness of breath with minimal exertion; } \\
\text { limiting instrumental ADL }\end{array}$ & $6(16)$ \\
\hline & $\begin{array}{l}3 \text { = Shortness of breath at rest; limiting self care } \\
A D L\end{array}$ & $1(3)$ \\
\hline & $\begin{array}{l}4 \text { = Life threatening consequences; urgent } \\
\text { intervention indicated }\end{array}$ & $0(0)$ \\
\hline \multicolumn{3}{|c|}{ Baseline dyspnoea grading (SABR treated patients) $(n=32)$} \\
\hline & $0=$ No dyspnoea & $4(12)$ \\
\hline & $1=$ Shortness of breath with moderate exertion & $22(69)$ \\
\hline & $\begin{array}{l}2 \text { = Shortness of breath with minimal exertion; } \\
\text { limiting instrumental ADL }\end{array}$ & $5(16)$ \\
\hline & $\begin{array}{l}3=\text { Shortness of breath at rest; limiting self care } \\
A D L\end{array}$ & $1(3)$ \\
\hline & $\begin{array}{l}4 \text { = Life threatening consequences; urgent } \\
\text { intervention indicated }\end{array}$ & 0 \\
\hline \multicolumn{2}{|c|}{ Previous history of malignancy $(n=30)$} & $10(33)$ \\
\hline \multicolumn{3}{|c|}{ Primary tumour site } \\
\hline & Central tumour & $6(16)$ \\
\hline & Peripheral tumour & $32(84)$ \\
\hline \multicolumn{3}{|c|}{ Histopathology Confirmation ( $\mathrm{n}=29$ ) } \\
\hline & Squamous cell carcinoma & $11(39)$ \\
\hline & Adenocarcinoma & $13(43)$ \\
\hline & Large cell undifferentiated & $1(4)$ \\
\hline & Bronchoalveolar carcinoma (BAC) & 0 \\
\hline & $\begin{array}{l}\text { Others (poorly differentiated carcinoma, mix } \\
\text { non-small cell/large cell carcinoma) }\end{array}$ & $4(14)$ \\
\hline & & Median (range) \\
\hline \multicolumn{2}{|c|}{ Age in years } & $75.5(51-89)$ \\
\hline \multicolumn{2}{|c|}{ ECOG status } & $1(0-2)$ \\
\hline \multicolumn{2}{|c|}{ Smoker pack/years $(n=35)$} & $40(10-125)$ \\
\hline \multicolumn{2}{|c|}{ Primary tumour size (mm) } & $29(1.6-52)$ \\
\hline \multicolumn{2}{|c|}{ Charlson Comorbidity Index } & $1(0-4)$ \\
\hline \multicolumn{3}{|c|}{ Baseline Spirometry $(n=37)$} \\
\hline & FEV1 actual (L) & $1.4(0.34-3.8)$ \\
\hline
\end{tabular}

This article is protected by copyright. All rights reserved. 


\begin{tabular}{|l|l|c|}
\hline & predicted \% & $65.7(21-105.2)$ \\
\hline & FVC actual (L) & $2.68(0.81-5.13)$ \\
\hline & predicted \% & $90(36-119)$ \\
\hline & DLCO predicted \% (n=33) & $55.2(16.6-131)$ \\
\hline
\end{tabular}

\begin{tabular}{|c|c|c|c|c|c|}
\hline$n=35$ & G0 & G1 & G2 & G3 & G4 \\
\hline Atelectasis & 25 & 9 & 0 & 1 & 0 \\
\hline Bronchopulmonary haemorrhage & 34 & 1 & 0 & 0 & 0 \\
\hline Cough & 14 & 18 & 3 & 0 & 0 \\
\hline Dyspnoea & 8 & 15 & 11 & 1 & 0 \\
\hline Hypoxia & 32 & 2 & 1 & 0 & 0 \\
\hline Pleural effusion & 33 & 2 & 0 & 0 & 0 \\
\hline Pneumonitis & 32 & 1 & 1 & 1 & 0 \\
\hline Pulmonary fibrosis & 25 & 9 & 1 & 0 & 0 \\
\hline Dysphagia & 32 & 1 & 2 & 0 & 0 \\
\hline Dermatitis radiation & 34 & 1 & 0 & 0 & 0 \\
\hline Chest wall pain & 24 & 10 & 1 & 0 & 0 \\
\hline Bronchial fistula & 35 & 0 & 0 & 0 & 0 \\
\hline Bronchopleural fistula & 35 & 0 & 0 & 0 & 0 \\
\hline Pleural haemorrhage & 35 & 0 & 0 & 0 & 0 \\
\hline Tracheal fistula & 35 & 0 & 0 & 0 & 0 \\
\hline Pericardial effusion & 35 & 0 & 0 & 0 & 0 \\
\hline Esophageal fistula & 35 & 0 & 0 & 0 & 0 \\
\hline Esophageal stenosis & 35 & 0 & 0 & 0 & 0 \\
\hline Esophageal ulcer & 35 & 0 & 0 & 0 & 0 \\
\hline Superficial soft tissue fibrosis & 35 & 0 & 0 & 0 & 0 \\
\hline Brachial plexopathy & 35 & 0 & 0 & 0 & 0 \\
\hline
\end{tabular}




\begin{tabular}{|c|c|c|c|c|c|c|c|c|c|}
\hline \multirow{2}{*}{\multicolumn{3}{|c|}{ All patients $n=38^{*}$}} & \multicolumn{6}{|c|}{ Follow up dyspnoea grading } & \multirow[b]{2}{*}{ Total } \\
\hline & & & 0 & 1 & 2 & 3 & 4 & Unknown & \\
\hline \multirow{6}{*}{$\begin{array}{l}\text { Baseline } \\
\text { dyspnoea } \\
\text { grading }\end{array}$} & & 0 & 2 & 5 & 0 & 0 & 0 & 2 & 9 \\
\hline & & 1 & 6 & 10 & 5 & 0 & 0 & 1 & 22 \\
\hline & & 2 & 0 & 0 & 6 & 0 & 0 & 0 & 6 \\
\hline & & 3 & 0 & 0 & 0 & 1 & 0 & 0 & 1 \\
\hline & 4 & & 0 & 0 & 0 & 0 & 0 & 0 & 0 \\
\hline & Total & & 8 & 15 & 11 & 1 & 0 & 3 & 38 \\
\hline
\end{tabular}




\section{University Library}

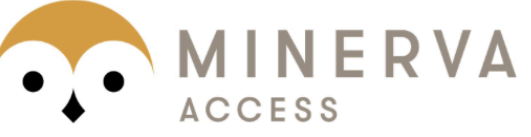

A gateway to Melbourne's research publications

Minerva Access is the Institutional Repository of The University of Melbourne

\section{Author/s:}

Hau, E;Hegi-Johnson, F;Atkinson, C;Barber, J;Browne, LH;Chin, Y;Dwyer, P;Graham, $\mathrm{PH}$;O'Hare, J;Lu, D;Rains, M;Ragusa, C;Schmidth, L;Small, K;Unicomb, K;West, K;White, S;Last, A;Ludbrook, J;Azzi, M;Aherne, NJ;Van Tilburg, K;Vinod, S;Ma, X;Yeghiaian Alvandi, $\mathrm{R}$

Title:

Collaborative implementation of stereotactic ablative body radiotherapy: A model for the safe implementation of complex radiotherapy techniques in Australia

Date:

2019-11-27

\section{Citation:}

Hau, E., Hegi-Johnson, F., Atkinson, C., Barber, J., Browne, L. H., Chin, Y., Dwyer, P., Graham, P. H., O'Hare, J., Lu, D., Rains, M., Ragusa, C., Schmidth, L., Small, K., Unicomb, K., West, K., White, S., Last, A., Ludbrook, J. ,... Yeghiaian Alvandi, R. (2019). Collaborative implementation of stereotactic ablative body radiotherapy: A model for the safe implementation of complex radiotherapy techniques in Australia. ASIA-PACIFIC JOURNAL OF CLINICAL ONCOLOGY, 16 (1), pp.39-44. https://doi.org/10.1111/ajco.13277.

Persistent Link:

http://hdl.handle.net/11343/286671 